Conmemoración de la promulgación del Código Civil peruano 



\section{El régimen de la propiedad rural en el Perú de fines del siglo XX}

\section{Guillermo García Montúfar Sarmiento Martha Silva Díaz}

\section{Origen y concepto de la propiedad. Evolución}

\subsection{Origen y concepto}

Existen diversas conceptualizaciones en torno al derecho de propiedad, las cuales han variado desde su reconocimiento como tal en el ámbito jurídico hasta la actualidad.

De Trazegnies (1978) conceptualiza este derecho en la forma siguiente:

Entendemos la propiedad como una de las tantas formas históricas de regulación social, es decir, como un sistema de derechos y obligaciones que varía con el tiempo, que adquiere diferentes significaciones concretas, y que no tiene otro sentido que el que los hombres de una determinada época quieren darle. [En tal sentido, añade que] si queremos saber lo que es verdaderamente la propiedad tenemos que preguntarnos cuáles son los derechos y obligaciones efectivos que tiene el propietario frente a la cosa en una determinada sociedad. (pp. 76-78)

Nuestro ordenamiento jurídico encuentra sus antecedentes en las instituciones del derecho romano. Sin embargo, en el derecho romano no se definió el derecho de propiedad. Petit (1996) advierte que la falta 
de definición de este derecho se explica porque la propiedad escapa a toda definición por su sencillez y extensión, pues es el derecho más completo que se pueda tener sobre una cosa corporal [cursivas añadidas] (p. 229).

Al respecto, Jörs y Kunkel (1937) señalan:

[En Roma] la jurisprudencia clásica entendía por propiedad la dominación jurídica, exclusiva e ilimitada, de una cosa [cursivas añadidas]. Se reconocía, pues, a la propiedad por los beneficios que producía, resumidos en el uso, el disfrute y el abuso. De acuerdo con dicha conceptualización, el propietario contaba con un poder absoluto sobre la cosa, aunque desde ya se contemplaban algunas restricciones legales ${ }^{1}$. Asimismo, se reconoció la facultad del propietario de restringir su derecho sobre la cosa mediante la concesión a favor de terceros de las ventajas de que goza. Esta concesión podía comprender todo o parte del ius utendi y del ius fruendi, quedando siempre en el propietario el ius abutendi. (p. 172)

En cuanto a la extinción del derecho de propiedad, esta se producía, en el caso de los inmuebles, únicamente cuando ocurría su destrucción total o su desaparición. Así pues, la característica esencial de este derecho era la perpetuidad, pudiendo transmitirse, mas no extinguirse.

De otro lado, los romanos no habrían conocido la expropiación por causa de utilidad pública, aunque, como indica Petit (1996), "se encuentran ciertos casos en que los particulares han sido expropiados por interés general; por ejemplo, la reparación o arreglo de los acueductos de Roma para el restablecimiento de una vía pública" (p. 230).

\subsection{Evolución}

En la época medieval, los señores feudales entregaron sus propiedades parceladas a terceras personas (vasallos), a fin de que las usen a cambio de una renta; esta entrega era de carácter perpetuo. Más adelante, se abandonó la noción del feudo y se acentuó el individualismo al partirse la propiedad feudal en dos: el dominio directo y el dominio útil, lo que dio como resultado dos propietarios del mismo bien.

1 A modo de ejemplo, la Ley de las XII Tablas prohibía al propietario cultivar su campo o edificar hasta la línea divisoria de los fundos vecinos, debiendo dejar libre un espacio de dos pies y medio. Igualmente, lo obligaba a abstenerse de hacer trabajos que pudiesen cambiar el curso de las aguas de lluvia. 
La nueva noción de propiedad se trasladó a nuestro país, puesto que, como señala Guevara (2012), "a partir de esta distinción conceptual se desarrollaron las más variadas formas de explotación económica y disfrute legal de las haciendas coloniales, entre ellas las censales" (p. 276). Entre las modalidades utilizadas en el Perú durante la Colonia, se encuentran los censos enfitéuticos, consignativos y reservativos, los mayorazgos, las capellanías y los patronatos eclesiásticos, que impedían la libre transmisión de los bienes. Al respecto, Ramos Núñez sostiene que mediante estas modalidades de explotación de la propiedad:

El bien perdía valor comercial y se desalentaba su incorporación al tráfico inmobiliario. [Añade, además, que] al fenecimiento de los mayorazgos, capellanías y patronatos legos o eclesiásticos se denominaría desvinculación de la propiedad; mientras que al término o fin del dominio compartido en el censo enfitéutico, consignativo o reservativo se le llamó consolidación del dominio, redención de la propiedad o desamortización. (Como se citó en Guevara, 2012, pp. 278-279)

Posteriormente, con la Revolución francesa se produjo en Europa una verdadera reforma agraria, que consagró como propietarios a los vasallos, ya que estos, en la práctica, habían adquirido todas las ventajas jurídicas de la propiedad (De Trazegnies, 1976, p. 84).

La conceptualización clásica de la propiedad liberal moderna proviene del Código de Napoleón, expresión jurídica del pensamiento burgués de la Revolución francesa. Así, el artículo 544 de este código definió a la propiedad como "el derecho de gozar y de disponer de las cosas de la manera más absoluta dentro de los límites establecidos por las leyes". En similares términos, el artículo 850 del Código Civil peruano (1936) señalaba que "el propietario de un bien tiene derecho a poseerlo, percibir sus frutos, reivindicarlo y disponer de él dentro de los límites de la ley". De Trazegnies (1976) acota que "la propiedad liberal se caracteriza por su perpetuidad e independencia. En realidad, se trata de un derecho de disposición puro, incondicional, no sujeto a plazo ni a vinculaciones ajenas a su propia naturaleza. [En tal sentido, añade que] una propiedad temporal no es propiedad en sentido clásico" (p. 82).

Sin embargo, se debe reconocer que la propiedad absoluta ha sufrido progresivas limitaciones en el tiempo, no solo las derivadas de las relaciones de vecindad -ya abordadas por el derecho romano-, sino 
también de aquellas que tienen que ver con la introducción de conceptos como la necesidad o utilidad pública o el interés social.

Una de las ideas desarrolladas a partir del siglo XX es la de explotación económica de los bienes. Como señala López Jacoiste:

La urgencia por conseguir una productividad máxima en cuanto que es factor de un beneficio social ha traído como secuela la idea de explotación, que equivale a extracción del máximo rendimiento posible de las cosas o de la mayor utilidad que puedan proporcionar. [De igual manera, sostiene que la idea de explotación se contrapone a la idea de mero uso y que] la necesidad de explotar es la expresión concreta de la función social, que gravita sobre la titularidad de ciertos derechos de carácter patrimonial, y en especial, de los derechos reales. (Como se citó en Díez-Picazo, 1995, pp. 821-823)

En lo referente a los predios agrarios, Díez-Picazo (1995) indica que "en las modernas leyes agrarias apunta la idea de una obligación de explotar las fincas o mejorarlas -o por lo menos la carga de hacerlo asíacompañada con el peso impresionante de la expropiación que puede producirse en otro caso"' (p. 823).

\section{Tratamiento constitucional de la propiedad}

La protección constitucional del derecho de propiedad en el Perú ha evolucionado bajo diversos matices, principalmente en lo que concierne al régimen de la propiedad agraria.

La Comisión designada con fecha 7 de agosto de 1931, con la finalidad de proponer un anteproyecto de un nuevo texto constitucional, expresó:

No cabe ya sostener el carácter absoluto de la propiedad de la tierra y demás factores de la producción. Ha caducado el antiguo principio de la propiedad concebida como derecho ilimitado de uso y abuso de las cosas. Es la propiedad, en cierto aspecto, un derecho, en otro, una función a cargo del propietario; sobre todo tratándose de la tierra o el capital.

Figallo (1994) considera que dicha Comisión planteaba el inicio de una reforma agraria, pues proponía que el Estado favorezca la conservación y difusión de la pequeña y mediana propiedad rural, y facultaba la 
dación de leyes especiales que autorizaran la expropiación de tierras de dominio privado, especialmente las no explotadas o mal cultivadas, para subdividirlas y enajenarlas en las condiciones que fijase la ley (p. 216).

Con posterioridad, la Constitución peruana (1933) reguló, en su artículo 29, el derecho de propiedad bajo la siguiente forma: "La propiedad es inviolable, sea material, intelectual, literaria o artística. A nadie se puede privar de la suya sino por causa de utilidad pública probada legalmente y previa indemnización justipreciada".

Esta regulación encuentra sus antecedentes en las Constituciones de 1856, 1860, 1867 y 1920. Sin embargo, la antes citada disposición y las contenidas en los artículos 34 y 47 de la misma Constitución fueron modificadas por la Ley 15242 (1964) poco después de la entrada en vigencia de la Ley 15037, Ley de Reforma Agraria (1964). La finalidad de la modificación constitucional fue, como bien señala Figallo (1994), "de viabilizar sin tropiezos las disposiciones contenidas en la Ley 15037" (p. 29).

El nuevo texto del artículo 29 antes citado quedó redactado con el siguiente tenor:

La propiedad es inviolable. A nadie se puede privar de la suya sino en virtud de mandato judicial o por causa de utilidad pública o de interés social, probada legalmente y previa indemnización justipreciada. Cuando se trate de expropiación con fines de Reforma Agraria, irrigación, colonización o ensanche y acondicionamiento de poblaciones, o de expropiación de fuentes de energía o por causa de guerra o calamidad pública, la ley podrá establecer que el pago de la indemnización se realice a plazos o en armadas o se cancele mediante bonos de aceptación obligatoria. La ley señalará los plazos de pago, el tipo de interés, el monto de la emisión y las demás condiciones a que haya lugar; y determinará la suma hasta la cual el pago de la indemnización será hecha necesariamente en dinero y previamente. (Ley 15242, 1964)

Con esta modificación, la Constitución de 1933 delegó en una futura ley la tarea de normar las limitaciones al ejercicio de la propiedad. A decir de Pásara (1973): "Para ello se usó lo que en derecho se denomina una fórmula standard: el interés social". No obstante, cabe señalar que el término interés social no supuso la mera incorporación de un concepto que deba entenderse en su sentido genérico o ideal; más bien, implicó un decisivo alejamiento de la concepción individualista del derecho de pro- 
piedad, orientado a favorecer a determinados sectores de la sociedad hasta entonces excluidos de la propiedad agraria. En la misma línea, la modificación del artículo 47 de la Constitución peruana (1933) impuso una limitación a la extensión de la propiedad en los términos siguientes:

El Estado favorecerá la conservación y difusión de la pequeña y mediana propiedad rural. La ley fijará la extensión máxima de tierra de que puede ser dueño una sola persona natural o jurídica, según el tipo de explotación a que la tierra se dedique y tomando en cuenta las peculiaridades demográficas, sociales y geográficas de cada zona o región, así como las condiciones naturales y técnicas de producción.

El Estado dará el apoyo económico y técnico necesario para desarrollar la propiedad rural y los sistemas cooperativo y comunitario de explotación y comercialización. (p. 212)

Como se aprecia, las reformas indicadas, introducidas en la Constitución de 1933, estaban destinadas a servir de sustento a un proceso de reforma agraria que implicara la modificación sustancial de la estructura de la propiedad de las tierras rurales, basándose en el concepto de interés social como causa justificativa de la expropiación, del pago de la indemnización mediante bonos y en forma diferida, y del establecimiento de límites en la extensión de la propiedad agraria.

\section{La nueva estructura de la propiedad agraria durante la vigencia de la Ley 17716, Ley de Reforma Agraria, sus disposiciones reglamentarias y conexas}

Cinco años después de las reformas a la Constitución de 1933 antes comentadas, se promulgó el Decreto Ley 17716, Ley de Reforma Agraria, cuyo Texto Único Ordenado se aprobó al año siguiente, mediante Decreto Supremo 265-70-AG.

El artículo 1 del Decreto Ley 17716 (1969) definió a la reforma agraria como el "instrumento de transformación de la estructura agrícola del país". Se estableció como sus finalidades las siguientes:

(i) Sustituir los regímenes de latifundio y minifundio por un sistema justo de propiedad, tenencia y explotación de la tierra.

(ii) Lograr que la tierra constituya para el hombre que la trabaja base de su estabilidad económica. 
Al respecto, Rubio Correa (1972) comenta: “El artículo 1 vinculó tres conceptos que tienen una clara distinción en Derecho: propiedad, tenencia y explotación, conceptos que la Ley trató efectivamente de unir mediante mecanismos muy estrictos" (p. 169).

El artículo 3 del Decreto Ley 17716 (1969) dispuso que la legislación agraria debía contener:

(i) La regulación del nuevo derecho de propiedad de la tierra para que se use en armonía con el interés social.

(ii) El establecimiento de las limitaciones a que está sujeta la propiedad rural.

En el artículo 5 del Decreto Ley 17716 (1969), se declaró de utilidad pública y de interés social la expropiación de predios rústicos de propiedad privada en las condiciones establecidas expresamente en ella.

En cuanto a las limitaciones establecidas a la propiedad rural, el artículo 10 del Decreto Ley 17716 (1969) definió a la afectación como la limitación del derecho de propiedad rural impuesta con fines de reforma agraria, en forma expresa e individualizada, respecto de la totalidad o parte de un predio para su expropiación por el Estado y su posterior adjudicación a campesinos debidamente certificados.

De otro lado, el mismo decreto ley incorporó disposiciones relativas a la extinción del derecho de propiedad rural, distintas de las contempladas en la normativa civil, las cuales implicaban un cambio radical en el concepto del derecho de propiedad. Asimismo, se modificó el concepto de uso de los predios rurales regulado por la normativa civil, así como las características de la posesión requerida para la adquisición por prescripción de la propiedad agraria. En este aspecto, el artículo 8 del Decreto Ley 17716 (1969) dispuso que las tierras abandonadas por sus dueños quedaban incorporadas al dominio público. Las causales que daban lugar al abandono pueden resumirse así:

- No uso de la propiedad en armonía con el interés social conforme al artículo 34 de la Constitución de $1933^{2}$.

2 Conforme al texto modificado del artículo 34 de la Constitución de 1933, "la propiedad debe usarse en armonía con el interés social. La ley fijará los límites y modalidades del derecho de propiedad". 
- No cultivo durante tres años consecutivos, mediante sementeras o plantaciones o crianza de ganado de acuerdo con la capacidad de los pastos, efectuados por su dueño u otro en su nombre.

- $\quad$ En caso de cultivo parcial, la extinción se producía respecto de la parte inculta.

- Uso durante más de un año por campesinos que no tuviesen vínculo contractual con el propietario sin que este hubiere interpuesto la acción judicial respectiva.

Como correlato de la regulación de la extinción de la propiedad rural en virtud del abandono, el mismo artículo 8 estableció la adquisición de tierras rústicas por prescripción durante el término de cinco años, siempre que el poseedor las hubiese poseído para sí en la forma indicada en el acápite precedente.

Del mismo modo, el artículo 15 del Decreto Ley 17716 (1969) implementó la aplicación del artículo 34 de la Constitución de 1933, estableciendo los supuestos en los cuales no se consideraba que la propiedad rural se usaba en armonía con el interés social:

(i) Abandono de la tierra o deficiente explotación, así como mal manejo o deterioro de los recursos naturales.

(ii) Subsistencia de formas antisociales o feudatarias de explotación de la tierra.

(iii) Condiciones injustas o contrarias a la ley en las relaciones de trabajo.

(iv) Concentración de la tierra de manera tal que constituya un obstáculo para la difusión de la pequeña y mediana propiedad rural y que determine la extrema o injusta dependencia de la población respecto del propietario.

(v) El minifundio o la fragmentación del predio en forma que determine el mal uso o la destrucción de los recursos naturales, así como el bajo rendimiento de los factores de la producción.

En un análisis efectuado en los inicios de la reforma agraria de los setenta, Pásara (1973) comenta:

Tratándose de las limitaciones a la propiedad rural, hay varias instituciones en las que importa detenerse. La primera de ellas es el 
abandono. La Ley creó esta figura de acabamiento de la propiedad por desuso, que es nueva en el ordenamiento jurídico en tanto que por el simple no uso de la propiedad ésta pasa al dominio público. Las limitaciones al derecho de propiedad por el interés social [...] son llevadas así al punto más alto por nuestro derecho. (p. 104)

En efecto, la extinción del derecho de propiedad en virtud del no uso -y, más aún, el no uso en la forma prevista por la ley-carecía de parangón en nuestra legislación y dio lugar a un verdadero quiebre en la estructura de la propiedad predial rural durante el tiempo de su vigencia (Pásara, 1973, p. 104).

Paralelamente, Rubio Correa (1972) analiza también las principales modificaciones al derecho de propiedad introducidas por la legislación agraria de los setenta, con respecto a las normas que establecía el Código Civil. Así, señala que, a diferencia de la normativa civil, para tener derecho a "la conservación de la propiedad de las tierras agrarias no basta sólo el tener justo título, sino que es indispensable trabajar directamente la tierra" (p. 170), a partir de lo cual se colige que no se admitía que quedara inculta por el plazo establecido.

Esta exigencia al propietario, denominada conducción directa, era una de las condiciones esenciales para tener y mantener la propiedad agraria. Esta condición o requisito estuvo vigente durante el período en el que rigió la legislación agraria; fue recogida por el artículo 157 de la Constitución de $1979^{3}$, en el capítulo referido al régimen agrario.

El Decreto Ley 17716 (1969) estableció expresamente las características que debía tener la conducción o explotación directa. Señalaba que se entendían como tales las siguientes situaciones:

(i) Si el propietario trabajaba personalmente la tierra con ayuda de su familia, constituyendo este trabajo su actividad básica, cuando el área que poseyese no excediera del triple de la unidad agrícola familiar.

3 Artículo 157.- El Estado garantiza el derecho de propiedad privada sobre la tierra, en forma individual, cooperativa, comunal, autogestionaria o cualquiera otra forma asociativa, directamente conducida por sus propietarios, en armonía con el interés social y dentro de las regulaciones y limitaciones establecidas en las leyes. Hay conducción directa cuando el poseedor legítimo o inmediato tiene la dirección personal y la responsabilidad de la empresa. Las tierras abandonadas pasan al dominio del Estado para su adjudicación a los campesinos sin tierras. 
(ii) Si el propietario dirigía personalmente la empresa agrícola de modo habitual, era responsable de la gestión financiera y aquella se encontraba registrada a su nombre para los efectos del cumplimiento de las leyes tributarias y laborales.

(iii) Si el predio pertenecía a una persona jurídica, se entendía que la dirección personal y la responsabilidad de la gestión financiera debían cumplirse por uno de los socios. Se presumía de pleno derecho que una persona no podía conducir más de un predio.

Como consecuencia de esta última presunción, también quedó limitado el derecho de propiedad agraria, en cuanto a la imposibilidad de que una misma persona pudiese tener o mantener más de un predio rural bajo su dominio.

Posteriormente, mediante el Decreto Ley 20136 (1973), se dictaron normas para la consolidación de la pequeña y mediana propiedad explotada por los dueños. En ellas se establecieron determinados requisitos para la conducción directa, atendiendo a la clasificación de la estructura agraria reformada descrita en el artículo 1 de dicho decreto ley.

A modo de ejemplo, para las superficies que no excedieran de 15 ha de tierras de cultivo bajo riego en la costa o de 5 ha en la selva y ceja de selva, cuyo titular los trabajase personalmente con ayuda de su familia (considerando como tales a los parientes comprendidos hasta el cuarto grado de consanguinidad y segundo de afinidad), sin requerir el empleo de mano de obra extraña, salvo en campaña agrícola, constituyendo este trabajo su actividad básica; se requería para considerar la existencia de conducción directa: (i) vivir en el predio, en un lugar vecino a este o en un centro poblado cercano; (ii) ejercer la posesión del predio; y (iii) ser propietario.

Dichas condiciones debían ser acreditadas mediante certificación de residencia expedida por la entonces Guardia Civil, la Policía de Investigaciones del Perú o la Guardia Republicana; la comprobación de la posesión que de oficio practicaría la Zona Agraria correspondiente y el título de propiedad. A falta de uno, la autoridad agraria presumía al poseedor como propietario.

El artículo 17 del Decreto Ley 20136 (1973) establecía que, en los casos de sucesiones indivisas originadas desde tres años antes de la declaración de Zona de Reforma Agraria, el juez de tierras debía proceder a la liquidación del condominio (léase copropiedad) a petición de 
parte, de la Dirección General de Reforma Agraria y Asentamiento Rural, o de oficio, adjudicándose el predio al condómino (léase copropietario) que lo hubiera estado trabajando directamente con su causante.

Quedó así modificada, para la propiedad predial agraria, la disposición contenida en el artículo 902 del Código Civil de 1936, que disponía que en el caso de condominios (léase copropiedad), resultaba improcedente que alguno de los condóminos (léase copropietarios) adquiriese el derecho a la propiedad del bien en razón a su uso exclusivo ${ }^{4}$.

En los casos en los cuales la Dirección General de Reforma Agraria hubiese efectuado la evaluación de los supuestos comprendidos en el Decreto Ley 20136, con ocasión de haber iniciado un procedimiento de afectación al amparo del Decreto Ley 17716, se encontraba facultada para identificar al condómino (léase copropietario) o condóminos (léase copropietarios) que ejercían la conducción directa del predio, sobre la base de la inspección ocular y demás pruebas documentales requeridas. Conforme a la legislación agraria que venimos comentando, eran estos quienes conservaban el derecho de propiedad sobre el predio, extinguiéndose dicho derecho respecto de los demás condóminos (copropietarios) que no se encontrasen trabajando directamente la tierra.

Como correlato a la conducción directa, la figura del abandono se incorporó a la legislación como una institución que extinguía el derecho de propiedad, cuyas causales ya hemos comentado. Al respecto, Rubio Correa (1972) señala:

El abandono [...] garantiza el cumplimiento de una finalidad esencial de la Reforma Agraria: que la tierra sea trabajada y que la propiedad de la tierra está indisolublemente unida a su tenencia y explotación. Si esto no se lleva a cabo, la ley sanciona extinguiendo el derecho de propiedad. (p. 171)

De otro lado, en cuanto a las características que debía revestir el uso de la propiedad rural para evitar su pérdida, cabe recordar que estas debían realizarse en armonía con el interés social. A decir de Rubio Correa (1972), tradicionalmente, "el uso antisocial de la propiedad sólo

4 Entre las medidas comentadas por Luis Pásara (1973), se señala que "se ha dispuesto asimismo que en la partición entre condóminos ordenada por la ley (D. L. 17716;21 ${ }^{\circ}$ ) tenga derecho preferente el que explote la tierra, y a falta de él, quien sea agricultor (D. L. $\left.18168 ; 7^{\circ}\right) "($ p. 11). 
ha dado lugar a la multa o castigo al propietario. Nunca dio paso a la expropiación. Cosa diferente sucede con la legislación agraria, donde es causal de pérdida de la propiedad rural" (p. 171).

Por lo que se refiere a la prescripción adquisitiva de dominio como modo de adquisición de la propiedad, el artículo 8 del Decreto Ley 17716 (1969) estableció como requisito objetivo para que operase a favor del poseedor que este realice la conducción directa del predio -con las características que hemos señalado-, con lo cual quedaron sin efecto los requisitos previstos en la normativa civil, muchos de ellos de carácter subjetivo. Además, como indicamos, el plazo para que operase la prescripción se acortó de diez o treinta años a solo cinco años, eliminándose la distinción entre la prescripción extraordinaria y la ordinaria.

La Constitución peruana (1979) definió en su artículo 159 a la reforma agraria como "el instrumento de transformación de la estructura rural y de promoción integral del hombre en el campo. Se dirige hacia un sistema justo de propiedad, tenencia y trabajo de la tierra, para el desarrollo económico y social de la Nación". Para ello reguló que el Estado debía:

(i) Prohibir el latifundio y, gradualmente, eliminar el minifundio mediante planes de concentración parcelaria.

(ii) Difundir, consolidar y proteger la pequeña y mediana propiedad rural privada, debiendo la ley fijar sus límites según las peculiaridades de cada zona.

(iii) Apoyar el desarrollo de empresas cooperativas y otras formas asociativas libremente constituidas para la producción, transformación, comercio y distribución de productos agrarios.

(iv) Dictar las normas especiales, que, cuidando el equilibrio ecológico, requiriese la Amazonía para el desarrollo de su potencial agrario, pudiendo otorgar tierras de esta región en propiedad o concesión a personas naturales o jurídicas de acuerdo a ley.

Por lo tanto, la Constitución de 1979 ratificó el régimen legal de la propiedad agraria consagrado a partir del Decreto Legislativo 17716. Al respecto, Figallo (1973) resaltó la vigencia de este régimen:

La función social es un nuevo límite del derecho de propiedad que trasciende las tradicionales limitaciones negativas impuestas por el 
derecho privado (relaciones de vecindad y servidumbres) o en resguardo del interés público (impuestos, expropiación, servidumbres administrativas). Ella impone obligaciones positivas de hacer al propietario. No recae sobre la esencia de los bienes, sino sobre su utilización. De modo que el fundamento de la propiedad se torna inseparable de su finalidad. (p. 233)

\section{El fin del régimen legal de la reforma agraria}

La estructura de la propiedad agraria, descrita en la sección anterior, fue paulatinamente desarticulada a partir de los ochenta. Así, el Decreto Legislativo 002 de fecha 17 de noviembre de 1980, Ley de Promoción y Desarrollo Agrario, dispuso la conclusión de los procesos de afectación de predios rústicos con fines de reforma agraria dentro del término perentorio de 90 días, y estableció la presunción de que, una vez vencido este, eran inafectables, sin necesidad de resolución expresa, salvo que se comprobara que no se encuentren directamente conducidos.

En los noventa, el Decreto Legislativo 653, Ley de Promoción de las Inversiones en el Sector Agrario, promulgado con fecha 30 de julio de 1991, derogó expresamente el Decreto Ley 17716 y sus normas reglamentarias y conexas, con excepción de los artículos referidos a los órganos jurisdiccionales hasta que se produjese la aprobación de la Ley Orgánica del Poder Judicial.

El Decreto Legislativo 653 (1991) tuvo como objetivo otorgar las garantías necesarias para el libre desarrollo de las actividades agrarias realizadas por personas naturales o jurídicas, sean nacionales o extranjeras. El artículo 2 de esta norma establece que "el Estado otorga seguridad jurídica sobre la tenencia y propiedad de las tierras rústicas. Los derechos reales sobre ellas se rigen por el Código Civil y las disposiciones contempladas en la presente Ley".

Entre las modificaciones sustanciales que trajo el Decreto Legislativo 653, podemos destacar el incremento de los límites inafectables y la modificación del concepto de conducción directa ${ }^{5}$. Esto implicó un distanciamiento del concepto recogido en el artículo 157 de la Constitución de 1979, en ese entonces vigente. Del mismo modo, se modificó

5 El Decreto Legislativo 653 considera que puede haber conducción directa por un arrendatario o por cualquier otra persona distinta del propietario. 
la normativa sobre arrendamiento, copropiedad y abandono de la propiedad rural.

En cuanto a la expropiación, el artículo 12 del Decreto Legislativo 653 dispuso que esta debía regirse por la Ley General de Expropiaciones y que el valor de las tierras expropiadas debía ser pagado a su valor de mercado y en efectivo, con lo cual se desterró el pago mediante bonos de la deuda agraria, cuya efectivización no se ha concretado en numerosos casos hasta la fecha.

En este escenario, se promulgó la Constitución Política vigente, aprobada por el Congreso Constituyente y ratificada en el referéndum del 31 de octubre de 1993. Esta Constitución consagró la protección al derecho de propiedad en términos distintos de los empleados en las Constituciones de 1933 y 1979 que hemos comentado, pues eliminaba, entre otros, el concepto de interés social y el contenido que este implica. Así, conforme al artículo 70 de la Constitución vigente (1993):

El derecho de propiedad es inviolable. El Estado lo garantiza. Se ejerce en armonía con el bien común y dentro de los límites de la ley. A nadie puede privarse de su propiedad sino, exclusivamente, por causa de seguridad nacional o necesidad pública, declarada por ley, y previo pago en efectivo de indemnización justipreciada que incluya compensación por el eventual perjuicio. Hay acción ante el Poder Judicial para contestar el valor de la propiedad que el Estado haya señalado en el procedimiento expropiatorio.

De otro lado, en cuanto al régimen agrario, se eliminó toda mención de la reforma agraria o del concepto de la conducción directa. El artículo 88 de la Constitución vigente (1993) dispone lo siguiente:

El Estado apoya preferentemente el desarrollo agrario. Garantiza el derecho de propiedad sobre la tierra, en forma privada o comunal o en cualquier otra forma asociativa. La ley puede fijar los límites y la extensión de la tierra según las peculiaridades de cada zona.

Las tierras abandonadas, según previsión legal, pasan al dominio del Estado para su adjudicación en venta.

Numerosos aspectos referidos a la aplicación del régimen agrario creado por el Decreto Ley 17716 han venido siendo cuestionados -muchos de ellos en cuanto a su presunta inconstitucionalidad- a través de procesos judiciales que se mantienen activos. 
Uno de los aspectos cuya discusión se ha prolongado hasta la actualidad es el pago del justiprecio en las expropiaciones mediante los bonos de reforma agraria. Al respecto, en la sentencia de fecha 15 de marzo de 2001, el Tribunal Constitucional declaró la inconstitucionalidad de los artículos 1 y 2, y de la Primera Disposición Final de la Ley 26597, así como la Disposición Transitoria Única de la Ley 26756, en la medida que dichas normas daban por cancelada la indemnización de la expropiación con la entrega de los bonos de reforma agraria y disponían que su pago debía efectuarse a valor nominal.

Es menester resaltar que, en la referida sentencia, el Tribunal Constitucional se pronunció, en primer lugar, en el sentido de que el pago efectuado mediante bonos era legítimo porque así se encontraba previsto en la Constitución de 1933 (artículo 29), con lo que respetaba el principio de aplicación de la ley en el tiempo. En segundo término, sin embargo, consideró que, conforme a un elemental criterio de justicia, debía exigirse una valoración y cancelación actualizada de la deuda, pero no se precisó el criterio para tal fin.

El criterio fue determinado mediante la sentencia del Tribunal Constitucional de fecha 16 de julio de 2013, en la que se dispuso que para el pago de bonos de la deuda agraria e intereses rige el criterio valorista o valor actualizado de los bonos. Para ello debía emplearse el método de actualización descrito en el fundamento 25 de dicha sentencia.

A manera de conclusión, advertimos que la propiedad es, en efecto, un concepto dinámico, cuya regulación responde a los intereses y necesidades de una determinada población en un determinado contexto histórico.

\section{Referencias}

Código de Napoleón (Código Civil francés). (2001). San José, Costa Rica: Investigaciones Jurídicas.

Constitución Política del Perú. (1979). Recuperado de http://spij.minjus. gob.pe/CLP/contenidos.dll?f=templates\&fn=default-constitucion. htm\&vid=Ciclope:CLPdemo

Constitución Política del Perú. (1993). Recuperado de http://spij.minjus. gob.pe/CLP/contenidos.dll?f=templates\&fn=default-constitucion. htm\&vid=Ciclope:CLPdemo

Decreto Ley 17716. Nueva Ley de Reforma Agraria. (24 de junio de 1969). Recuperado de http://faolex.fao.org/docs/pdf/per124295.pdf 
Decreto Supremo 265-70-AG. Texto Único Ordenado de la Nueva Ley de Reforma Agraria.

Decreto Ley 20136. (4 de setiembre de 1973). Recuperado de http://docs. peru.justia.com/federales/decretos-leyes/20136-sep-4-1973.pdf

Decreto Legislativo 002. Ley de Promoción y Desarrollo Agrario. (17 de noviembre de 1980).

Decreto Legislativo 653. Ley de Promoción de las Inversiones en el Sector Agrario. (30 de julio de 1991).

De Trazegnies, F. (1978). La transformación del derecho de propiedad. Derecho PUCP, 33, 75-104.

Díez-Picazo, L. (1995). Fundamentos del derecho civil patrimonial (tomo III). Madrid, España: Civitas.

Figallo, G. (1994). Derecho agrario peruano. Contenido e historia. Lima, Perú: Gráfica Horizonte.

Guevara, A. (2012). La propiedad agraria en el derecho colonial. En Estudios sobre la propiedad (pp. 265-282). Lima, Perú: Fondo Editorial de la Pontificia Universidad Católica del Perú.

Jörs, P., y Kunkel, W. (1937). Derecho privado romano. Madrid, España: Editorial Labor.

Ley 15242. (28 de noviembre de 1964). Recuperado de http://docs.peru. justia.com/federales/leyes/15242-nov-28-1964.pdf

Ley 15037. Ley de Reforma Agraria. (21 de mayo 1964). Recuperado de http://faolex.fao.org/docs/pdf/per124294.pdf.

Pásara, L. (1973). Propiedad social: la utopía y el proyecto. Derecho PUCP, 31, 211-237. Lima

Petit, E. (1996). Tratado elemental de derecho romano (12. ${ }^{a}$ ed.). México: Porrúa.

Rubio Correa, M. (1972). Modificaciones al derecho de propiedad en la legislación de reforma agraria. Derecho PUCP, 30, 169-176. 